\title{
Relating volatiles analysis by GC-MS to Oddy test performance for determining the suitability of museum construction materials
}

\author{
Michael J. Samide ${ }^{1 *}$, Mary C. Liggett', Jericha Mill ${ }^{1}$ and Gregory D. Smith² (1)
}

\begin{abstract}
Conservators' decisions regarding the suitability of museum construction materials for use in proximity to artworks still rely heavily on accelerated corrosion tests like the Oddy test despite widespread criticisms. These issues include inconveniently long wait times, sensitivity to only those pollutants capable of tarnishing metals, a general sense of unreliability, exaggerated environmental conditions, and subjectivity in assessing the test's results. Increasingly, alternative strategies that use instrumental approaches involving volatiles sampling coupled to gas chromatography with mass spectrometry (GC-MS) are being explored as faster, more comprehensive, potentially quantitative, and possible more 'objective' means of assessing the dangers of off-gassing from museum construction materials. While many of these characteristics are now well documented, the objectivity of the instrumental result is arguable. While the detection of volatiles and semi-volatiles by GC-MS can confidently yield a list of potential pollutants, "chemical intuition" must be used to predict whether many of the emitted compounds can in fact adversely affect artwork. In this study, evolved gas analysis (EGA) coupled to GC-MS is used to predict the suitability of a small sample set of plastics for use in a museum. The potential impact of volatiles observed in the EGA chromatogram was assessed using chemical reactivity principles and the sparse literature data on the material damages caused by a small group of known pollutants. These same plastics were then tested using the British Museum's 3-in-1 Oddy test. The prediction based on an educated chemical assessment of the compounds identified through instrumental analysis shows good correlation with pooled results from the Oddy test. In one of the two instances of disagreement, the EGA analysis was actually overly conservative and leaned toward prohibiting or restricting a material that passed the Oddy test. In the other, a material that failed the Oddy test but was passed by instrumental analysis was later shown to contain VOCs that could be considered corrosive. This trial suggests that with practice and experience instrumental approaches may be useful to supplement and perhaps one day supplant traditional accelerated corrosion testing of museum construction materials.
\end{abstract}

Keywords: Materials testing, Oddy test, Evolved gas analysis, Chromatography, Volatiles, Pollution, Degradation, Artwork

\footnotetext{
${ }^{*}$ Correspondence: msamide@butler.edu

${ }^{1}$ Chemistry Department, Butler University, 4600 Sunset Ave, Indianapolis,

IN 46208, USA

Full list of author information is available at the end of the article
} 


\section{Introduction}

Enclosures used for the storage, transport, and display of cultural heritage objects must be constructed from only non-corrosive and non-polluting materials [1-5]. Currently, construction materials are vetted by conservators based on the results of accelerated corrosion testing and microchemical testing [1] or by employing commercial protocols such as BEMMA, which make use of several ISO16000 procedures [2]. The former, known colloquially as the Oddy test, involves the exposure of three metal coupons $(\mathrm{Pb}, \mathrm{Cu}$, and $\mathrm{Ag})$ to the material in question for 28 days at elevated temperature $\left(60{ }^{\circ} \mathrm{C}\right)$ in a humid environment $(100 \% \mathrm{RH})$. Several variants and refinements of the British Museum's original Oddy test have been introduced over the years [5-9]. In all of these, subjective evaluation of the extent of corrosion of the metal coupons is used to rate a material as suitable for either permanent or temporary use in proximity to artwork or as unsuitable for use in the museum under most circumstances. The drawbacks of this test include the long wait before a result is generated, the detection of only those pollutants that will corrode metals, the lack of quantification of the unknown pollutants, exaggerated aging conditions, the time consuming nature of the test preparation, frequently compromised test containers, and the subjectivity in evaluating the test result. The frequently stated low cost advantage of Oddy testing must also be reconsidered as the price of ultrapure metals continues to climb and the cost of heavy metal waste disposal increases. These expenses are dwarfed by the cost in time and labor invested in preparing Oddy tests.

These concerns have prompted the search for alternative methods of material suitability testing, especially those that utilize chromatographic separations of the emitted compounds [10-20]. These approaches offer significant advantages in terms of speed and the comprehensive nature of the analysis, and they are also often seen as being a more objective assessment of the dangers posed by a material than that generated by the Oddy test. Admittedly, these tests can only be performed at institutions that have access to instrumentation, but the results of these analyses can be freely distributed to the larger community. For those institutions that already possess the requisite equipment, chromatographic analysis of pollution off-gassing can be significantly cheaper than traditional Oddy testing.

Evolved-gas analysis coupled to gas chromatography with mass spectrometry (EGA-GC-MS) was recently suggested as one such method to measure off-gassing from plastic materials that could damage artwork [21]. The EGA sampling approach had only rarely been used previously in cultural heritage chemistry [21, 22], and then largely for plastic identification purposes. This approach utilizes a microfurnace pyrolysis unit that is common in many museum laboratories that conduct GC-MS analysis of artists' materials. In this test, milligram quantities of the material are exposed to elevated, but not pyrolysis, temperatures in the EGA furnace for $30 \mathrm{~s}$ to several minutes. The volatile (VOCs) and semivolatile (SVOCs) organic compounds along with many inorganic gases (e.g. $\mathrm{HCl}$ ) that are thermally desorbed from the material are carried directly into the GC-MS for separation and identification. The entire experiment requires less than $25 \mathrm{~min}$ to complete and provides a comprehensive picture of the compounds that emanate from the polymer material under the brief exposure to accelerated thermal extraction temperatures. EGA provides several benefits over other volatiles sampling strategies for GC analysis that have been used in cultural heritage studies. Compared to static headspace sampling (HS), where the injection volume is fixed and limited, the EGA approach allows for extended pre-concentration of the analytes by extending the thermal extraction time of the desorption stage combined with cryo-trapping the evolved gases onto the GC column to enhance sensitivity. Unlike thermal desorption (TD) or solid phase microextraction (SPME) sampling approaches, which also incorporate a pre-concentration step, EGA analysis is amenable to all volatiles detectable by mass spectrometry without the need for one or more selective intermediary phases for pre-concentration.

Subjective grading of the degree of visible corrosion of an Oddy test coupon is routinely used to indicate the ability of a material to damage artwork. This feature is often criticized in the field of preventive conservation since the damage is not always gauged similarly by different analysts, and the test uses a high purity metal coupon as a proxy for all artists' materials-inorganic and organic artifacts. Instrumental analysis is often seen as a more rigorous testing method. EGA-GC-MS does provide a qualitative, and to some extent quantitative, rapid, and comprehensive identification of the volatile emissions of a material in question [23]. Importantly, like the BEMMA, ISO16000, and other instrument-based tests, this EGA methodology does not generally identify long term degradation products that might form over extended aging periods for the material under test, such as those formed under the exaggerated conditions of an Oddy test, unless they already exist in the sample when delivered to the lab for analysis.

Although most of the emitted gases can be identified by EGA-GC-MS with confidence, the physical and chemical reactivity of those VOCs on an artists' material have not necessarily been verified. The types of potential interactions from evolved gases are numerous, including corrosivity to metals, reactivity with pigments or media, 
softening of plastics, or catalysis of polymer degradation reactions, to name just a few. When deciding if a material's EGA analysis results indicate that the material could be deleterious, an assessment or judgement must still be made based on the analyst's understanding of the potential chemical reactivity of the suspect compound-what we refer to here as "chemical intuition," as well as their past experience with similar materials and knowledge of the limited published research regarding museum pollutants $[1,3,28]$. In this respect, a degree of subjectivity, albeit informed by science, is introduced into all instrumental analysis approaches.

In this work, our earlier application of EGA-GC-MS to plastic materials [23] has been extended to predict the outcome of the Oddy test for a small group of plastic samples with potential uses in museum construction projects. These predictions based on chemical intuition and literature references were then compared to the actual results from replicate Oddy tests performed on the same corpus of samples. The prediction of the Oddy test result based on instrumental analysis was achieved with good correlation on a sample set composed of common industrial polymers relevant to museum use.

\section{Experimental}

\section{EGA-GC-MS procedure for analysis of plastic materials}

EGA was performed using a Frontier PY-2020iD 'doubleshot' pyrolyzer. Between 1.5 and $30 \mathrm{mg}$ of sample filled a stainless steel Eco-cup sample holder (Frontier) that was purged with $\mathrm{He}$ for $\sim 5 \mathrm{~min}$, and then exposed to the $115{ }^{\circ} \mathrm{C}$ pyrolyzer furnace for $30 \mathrm{~s}$. Samples were used as received and studied in the form most likely to be seen in the museum environment. Sample mass differences were due to the inherent density of each material (foam, solid, laminate, etc.) that was used to fill the sample cup. Large differences in masses between different samples can be normalized for quantitative analysis if necessary. The thermal extraction temperature and time were selected to maximize sensitivity of the instrument while minimizing peak broadening. The $115^{\circ} \mathrm{C}$ extraction temperature ensures that thermal degradation of the materials is minimized. The furnace was interfaced at $215{ }^{\circ} \mathrm{C}$ to a GC inlet with a split ratio of 20:1. Emitted VOCs were trapped on the front end of a $40{ }^{\circ} \mathrm{C}$ Thermo TG-5MS capillary column $(30 \mathrm{~m} \times 0.25 \mathrm{~mm} \times 0.25 \mu \mathrm{m})$. In some instances cryo-trapping was required to retain and resolve highly volatile organic compounds and gases. This was accomplished using a Frontier Micro Jet Cryo-Trap (MJT 1030E) to cool the column to $-196{ }^{\circ} \mathrm{C}$ immediately after the inlet connection.

Chromatographic separation was accomplished on a Thermo Trace GC Ultra with a He carrier gas flow rate of $1.5 \mathrm{~mL} \mathrm{~min}^{-1}$. The oven temperature program was $40{ }^{\circ} \mathrm{C}$ for $3 \mathrm{~min}$; a $20{ }^{\circ} \mathrm{C} \mathrm{min}{ }^{-1}$ ramp to $150{ }^{\circ} \mathrm{C}$; a $10{ }^{\circ} \mathrm{C} \mathrm{min}^{-1}$ ramp to $250{ }^{\circ} \mathrm{C}$, and an isothermal hold for $6.5 \mathrm{~min}$. Detection of ions was accomplished using a Thermo ISQ mass spectrometer scanning a mass range of $29-31 \mathrm{~m} / \mathrm{z}$ for the first $2.2 \mathrm{~min}$ to detect formaldehyde, followed by a mass range of $45-450 \mathrm{~m} / \mathrm{z}$ for the remainder of the analysis. Identification of volatile components was performed using the NIST 08 Mass Spectral Search Program, ver. 2.0f. Duplicate or triplicate analyses of each material were performed and produced matching chromatograms. Peak heights were used as a semi-quantitative comparison of the relative amounts of volatiles observed within a single chromatogram, although strictly speaking no actual quantitation was performed in these studies.

\section{Oddy testing}

All Oddy tests were performed using a protocol similar to the modified British Museum 3-in-1 procedure [6]. Specifically, a $2 \mathrm{~g}$ sample of the material to be studied was placed in a $75 \mathrm{~mL}$ borosilicate boiling tube containing a smaller $0.8 \mathrm{~mL}$ borosilicate tube filled with deionized water (Milli-Q Direct 8). Freshly polished copper (Aldrich, $0.25 \mathrm{~mm}, 99.98 \%$ ), silver (Aldrich, $0.25 \mathrm{~mm}$, 99.9\%), and lead (Alfa Aesar, $0.1 \mathrm{~mm}, 99.998 \%$ ) coupons were fixed into small slits cut into the bottom of medicalgrade \#4 silicone stopper (SSI). The stopper was sealed onto the test tube using Parafilm reinforced with PTFE tape to prevent it from backing out while under pressure. Each sample and a control with no sample were studied in triplicate. The tubes were placed upright in a rack in a temperature controlled oven at $60{ }^{\circ} \mathrm{C}$ for 28 days.

At the end of each test period, the tubes were opened and the corrosion on the metal coupons was graded by three trained observers based on its severity as described by Robinet and Thickett [6]. The final grade for each replicate for each grader was determined by the coupon receiving the worst corrosion assessment. An average grade was then tabulated numerically from the triplicate runs by assigning a score of 1 for each Fail grade, 2 for temporary rating, and 3 for a pass assessment. Standard deviations were calculated based on the three experiments per sample. The actual Oddy test determination was then made based on the averaged result of the replicates. Because the averages often fell partway between the $\mathrm{F}, \mathrm{T}$, and $\mathrm{P}$ designations, the scale was divided in half steps to make intermediary scores of $\mathrm{F} / \mathrm{T}$ and $\mathrm{T} / \mathrm{P}$ possible.

\section{Samples}

The sixteen different plastics listed in Table 1 were studied in this work using both EGA-GC-MS and traditional Oddy testing. These commercially available materials were obtained from various departments within the 


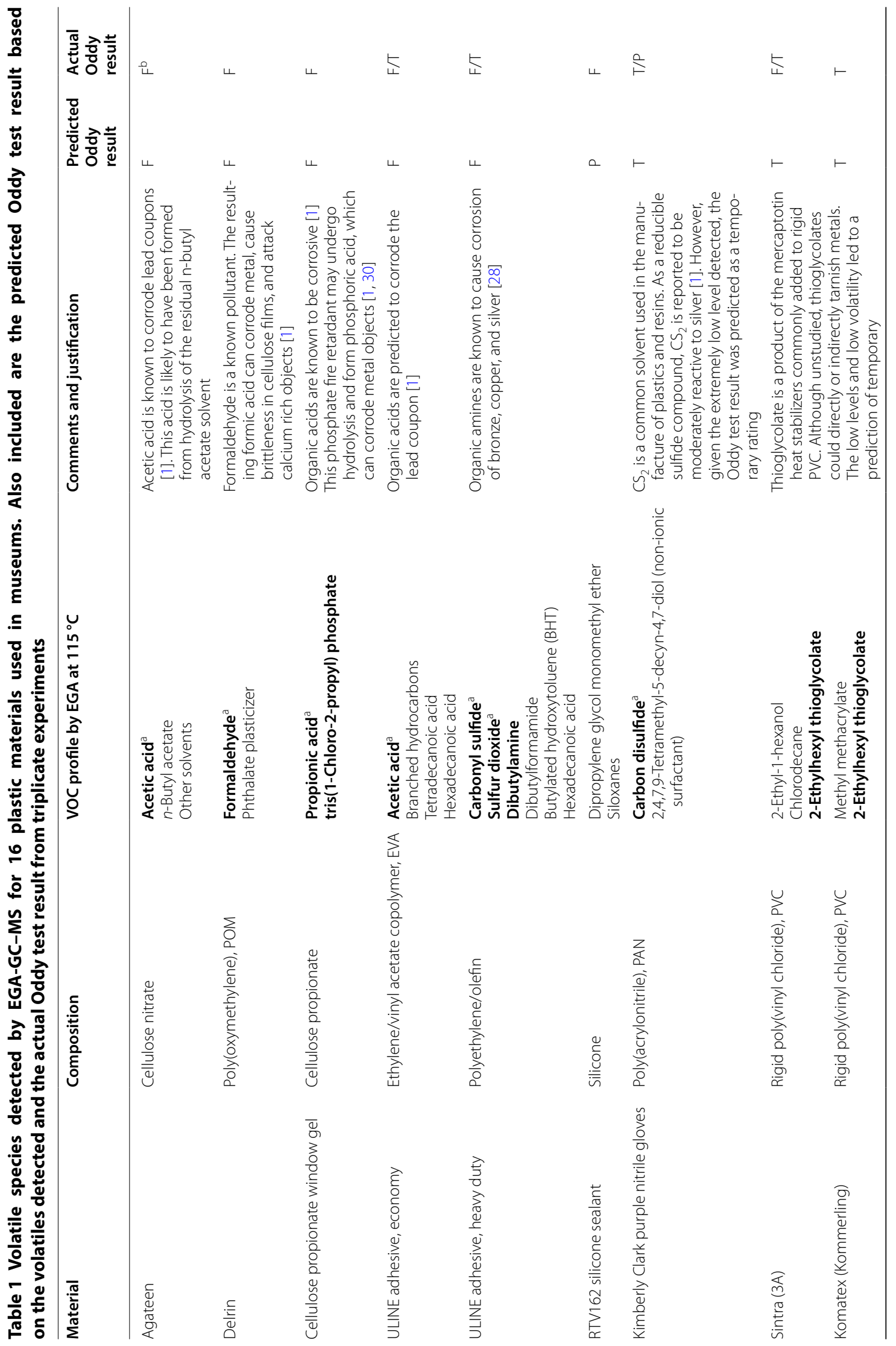




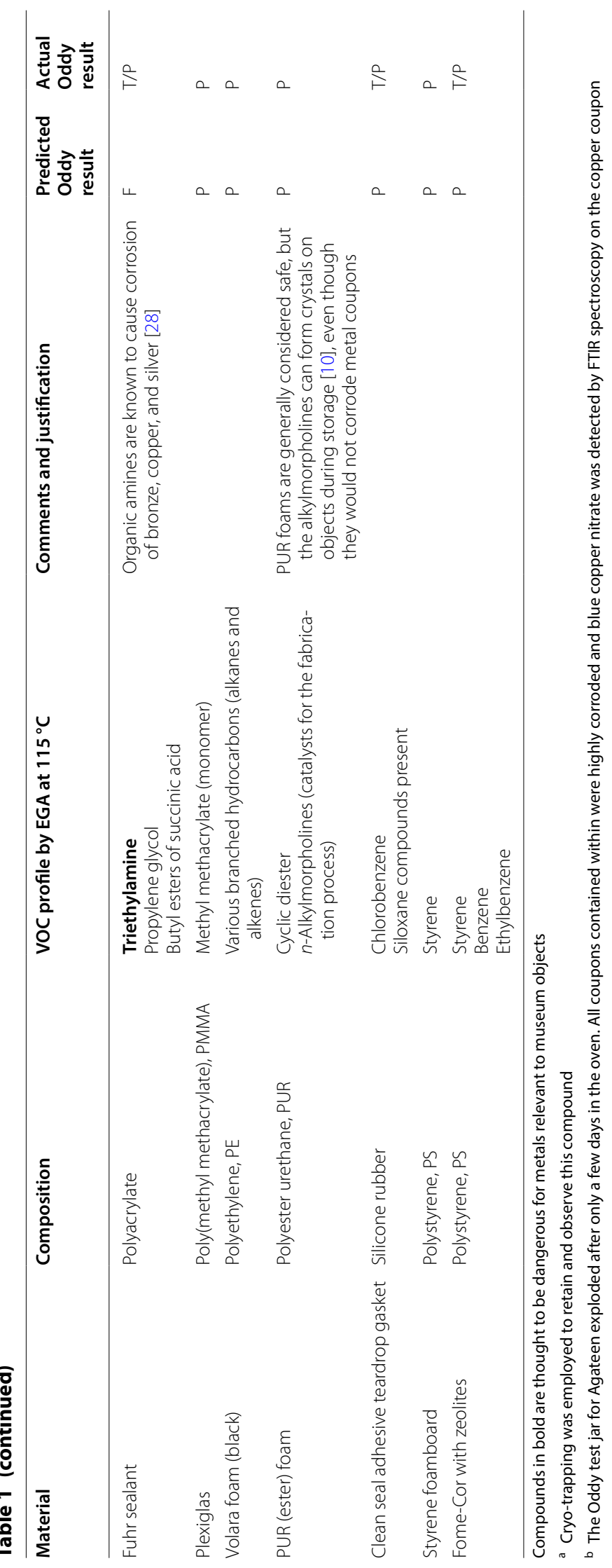


Indianapolis Museum of Art at Newfields (IMA) or from museum vendors. They represent construction materials either currently in use in the museum, previously used but no longer in use, or materials under consideration for use in display, storage, and shipping enclosures. For coatings, sealants, and glues, at least 4 weeks, but often several months, elapsed between casting out the material and its analysis. All materials were analyzed as small pieces using EGA, HS, and SPME sampling strategies with GC-MS, although only the EGA results are discussed here.

In addition to the plastic samples, numerous wood and wood composite materials such as oak, paulownia, birch plywood, and Medex were included in a larger overall set of sample materials. As expected, all of these wood-based materials failed the Oddy test badly and gave a positive microchemical test for organic acids. When analyzed by EGA-GC-MS using the cryo-trap, organic acids-primarily formic and acetic acids-were detected in the chromatogram, though poorly resolved on the non-polar TG-5MS column. While wood products are already well known to be a poor choice for museum storage and display enclosures [1], the evidence of acidic off-gassing provided by the instrumental analysis method is a noteworthy confirmation. However, because all of the wood samples failed the Oddy test and were predicted to fail based on the EGA data, the present study focused only on the subset of plastics for which less was known.

\section{Results and discussion}

The chromatogram generated by EGA analysis contains all of the volatile compounds that are desorbed at the thermal extraction temperature and which are amenable to GC separation and detection by MS. Compounds not amenable to this analysis, and therefore not identified for any of the materials studied, include but are not limited to ozone, peroxides, and reactive free radicals that would rapidly decompose in the microfurnace or react with the GC stationary phase. Figure 1 shows a typical EGA chromatogram obtained for the Lee colored window gel sample, which was previously determined by pyrolysisGC-MS to be a cellulose propionate sheet material. The three major peaks between 14.80 and $15.10 \mathrm{~min}$ are isomers of tris(1-chloro-2-propyl) phosphate (TCPP), a common material used as a plasticizer and fire retardant. Phosphate fire retardants and fire suppression chemicals have been implicated in corrosive reactions with metals [1]. Despite the relatively long EGA thermal extraction time of $30 \mathrm{~s}$, the peak shapes for these semi-volatile components is excellent, and baseline resolution is obtained. Detection of propionic acid at $4.0 \mathrm{~min}$ is accomplished using cryo-trapping, despite the volatile nature of the compound and its poor retention on the non-polar GC

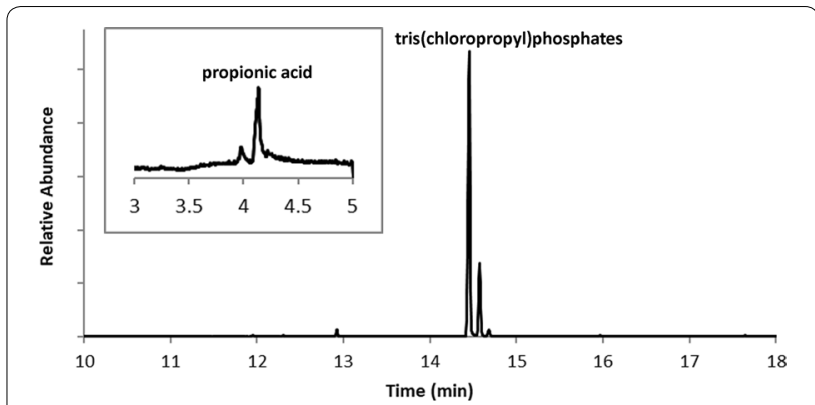

Fig. 1 EGA chromatogram for cellulose propionate window film. Major peaks are identified in the text and in Table 1

column used in this study. Volatile organic acids are also capable of reacting with metals and catalyzing degradation reactions in organic objects $[1,3]$.

Table 1 lists the sample corpus of sixteen different plastic materials that have previously been used or are currently used for the storage, transportation, handling, or display of museum objects at the IMA. Also provided in Table 1 are the major VOCs detected using the EGAGC-MS technique. These volatiles and semi-volatiles include unreacted monomers, residual solvents, and additives such as catalysts, stabilizers, fire retardants, or plasticizers used in the fabrication of the material or to modify its physical properties.

Although an extensive literature exists in the industrial hygiene field on the action of a wide range of VOCs on human health [24-27], corresponding information on the material reactivity of pollutants is scant. The adverse effect levels (AEL) of a handful of common museum pollutants such as ozone, mineral acids, $\mathrm{NO}_{x}$, hydrogen sulfide, and organic acids have been published, but only for their action on an equally small number of materials commonly found in artworks $[1,3,28]$. The prediction of material suitability based on the identity of emitted VOCs is therefore difficult since many other compounds could potentially cause unwanted changes to artworks including bleaching, color change, corrosion, softening, or depolymerization. Additionally, the concentration of the detected pollutant is generally unknown and would depend on release rate, enclosure volume, and leakage rate. Therefore the chemical cocktail off-gassed by a potential construction material must be assessed conservatively for its potential to cause harm to an artwork based on the extant literature and on the analyst's chemical intuition. This was tested using the EGA chromatograms of common plastic materials to predict the result of a traditional Oddy test. Those compounds identified by the instrumental analysis that were deemed to have the potential to cause corrosion to the Oddy test metal coupons are shown in bold-type in Table 1, along with 
a justification for the concern over their presence near artwork.

A predicted Oddy test result was generated using the identity of the VOCs detected as well as their relative peak intensities, although strictly speaking no quantitation of the specific volatiles was performed as part of this study. Many pollutants commonly found in the museum are known to be aggressively corrosive to metals and other artists' materials at even low levels, e.g., acetic acid or formaldehyde [1]. For these very corrosive VOCs, any amount observed in the EGA chromatogram triggered an "F-Fail" prediction with the expectation that the metal coupons in an Oddy test would be significantly tarnished. However, if the EGA analysis detected only a small peak for a compound that was not well known in the conservation literature, but deemed to be potentially corrosive based on fundamental chemical principles, the predicted Oddy test result would be a "T-Temporary." Finally, if only non-corrosive, relatively benign materials were identified, even if represented by a large chromatographic signal, the predicted Oddy test result was a "P-Pass." Importantly, this would not necessarily mean the material was harmless to all museum objects, as even relatively non-corrosive materials like residual solvents could cause unwanted softening or dissolution of important artists' materials in specific situations.
The predicted Oddy test results are shown in Table 1 immediately adjacent to the actual Oddy result from a triplicate analysis. Figure 2 graphically depicts the relationship between the predicted Oddy test result and the actual Oddy test result as gauged by three independent, trained observers who graded the Oddy test coupons. Predicted Oddy test results are shown as shaded bars: dark gray indicated a Fail, light gray a temporary grade, and white a pass result. The height of each bar represents the average actual average Oddy score $(\mathrm{F}, \mathrm{F} / \mathrm{T}, \mathrm{T} / \mathrm{P}$, or $\mathrm{P})$ presented numerically as calculated according to the method of Robinet and Thickett [6]. The error bars in Fig. 2 indicate one standard deviation from the three assessments. The large size of the error bars for some materials is noteworthy as an indication of the difficulty and subjectivity of conducting and grading Oddy tests.

The predicted Oddy result as determined by EGAGC-MS correlates well with the actual average Oddy result for most of these sixteen materials. Five of the six materials predicted to fail the Oddy test by the EGAGC-MS results actually failed the Oddy test. VOCs detected in the EGA analysis that suggested a failed Oddy test included formaldehyde, acids, phosphatebased fire retardants, and organic amines. Those materials predicted to pass the Oddy test emitted VOCs such as hydrocarbons (alkane and alkene), volatile blowing agents, residual solvents, and plasticizers. It is important

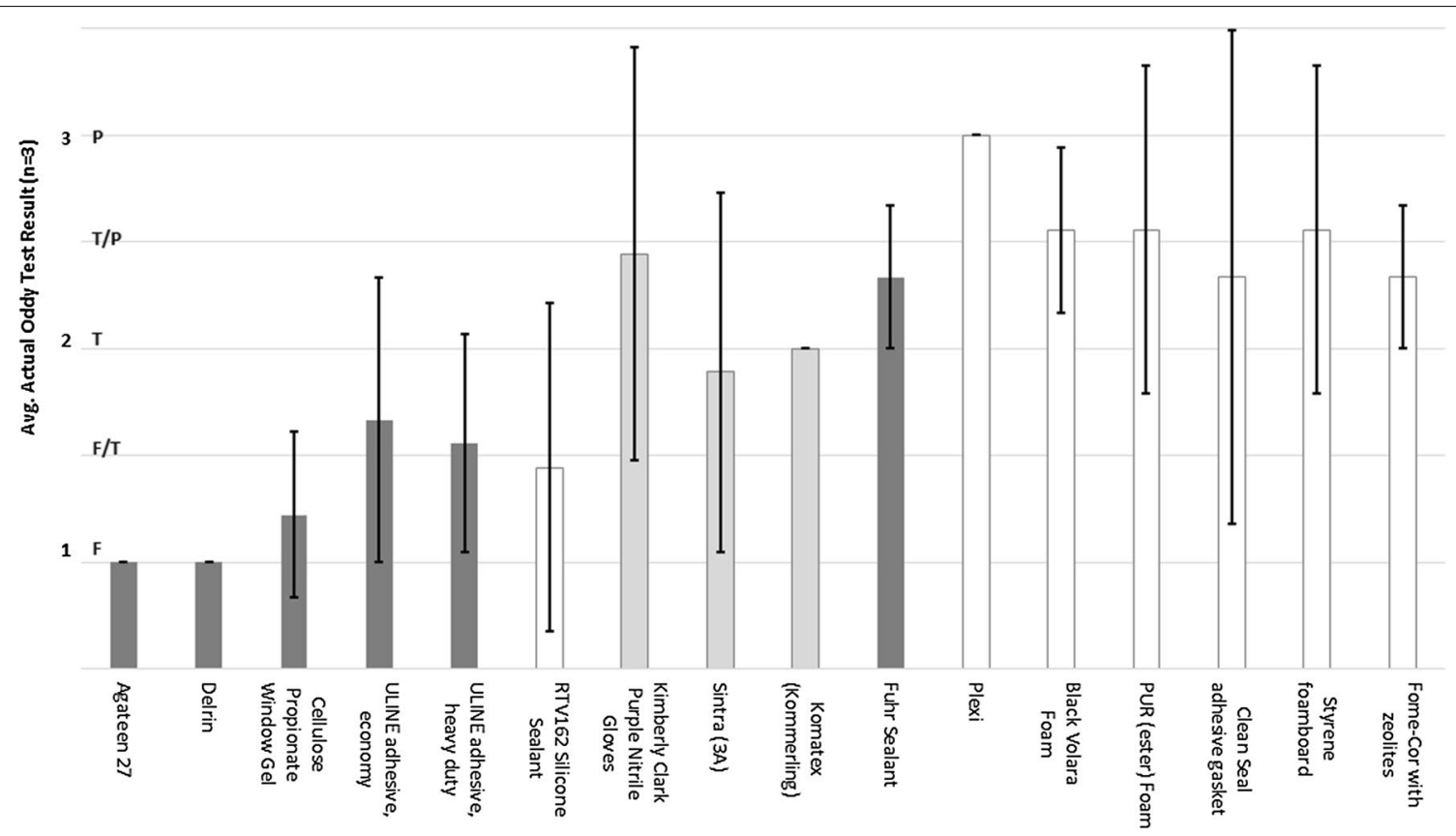

Fig. 2 Material suitability determined by EGA (shaded histogram bars) compared to actual averaged Oddy test results (height of histogram bars). Color indications are described in the text. Actual Oddy test result scores are displayed on the $y$-axis by the height of the histogram bars. Error bars indicate $1 \sigma$ of the average score and highlight the variability between trained readers along with variability in the test itself 
to note that plasticizers may be considered differently if the construction material would come into direct contact with an artwork since migration to the artwork's surface through contact is a very real concern for preservation [29].

EGA results from only two of the materials studied did not correctly predict the Oddy test result. EGA-GC-MS analysis of Fuhr water-borne acrylic sealant revealed the presence of triethylamine even after a substantial cure time of more than 6 months. Amines are known to interact in particular with copper [28], and so the material was expected to fail the Oddy test. In fact, the material was graded as a $\mathrm{T} / \mathrm{P}$-Temporary (score was 2.3 out of 3.0) in the actual Oddy test. This is fortuitous since the coating has previously passed an Oddy test at the IMA and is the regular barrier sealant applied to some wooden components of display cases and shipping crates at the institution. The instrumental test in this case identified a potential pollutant missed by the Oddy test, and highlights the utility of the EGA method to prompt further study into this material. To date, no specific metal artifact damage has been traced to the use of Fuhr sealant in the museum.

More surprising were the results from the analysis of RTV-162 silicone caulk. Product literature for this sealant indicates that the polymerization releases alcohol during the curing process, and the product is described as being non-corrosive to copper and brass in electronics. In these tests, the caulk had cured for 1 year, well beyond the 3-4 week off gassing period often dictated in museums for coatings, lacquers, and caulks prior to use in proximity to artworks [3]. The EGA-GC-MS analysis revealed the presence of primarily siloxanes in the fully cured product, and therefore a ' $\mathrm{P}$-Pass' was predicted. However, all Oddy tests showed surprisingly heavy corrosion of the copper and lead coupons, and the material subsequently failed repeated Oddy tests (score was 1.5 out of 3.0). Upon closer inspection of the EGA-GCMS chromatogram following the Oddy test replicates, minor peaks corresponding to trimethylamine, octanoic acid, 2,4-diethyl-6-methyltrioxane, and dibutylformamide were discovered. These peaks had been overlooked previously due to their very small peak height. In hindsight, these minor compounds could potentially have led to the corrosion noticed on the metal coupons, but each requires further study to confirm this suspicion. This observation is quite similar to that reported by Curran and co-workers, where the presence of a very minor component-acetic acid in a styrene object-was the major source of pollution [31]. The case of the silicone caulk highlights the improvement expected in the interpretation of EGA-GC-MS chromatograms with further experience and use of the technique in the field of cultural heritage.

These data suggest that EGA-GC-MS is an appropriate tool to predict material suitability for polymeric materials, and perhaps for other classes of construction materials. The suitability for use in proximity to artwork as indicated by the Oddy test was correctly predicted for all but two of the sixteen plastics (87.5\% accuracy) using this instrumental approach. For one of those exceptions, performance based on chemical intuition regarding the observed volatiles was overly conservative, with the material in fact performing better than predicted. In the other instance the prediction would have allowed a material to be used that clearly could damage metal artwork. As experience interpreting the EGA chromatograms increases, incidents such as this should be less frequent. For the corpus of samples tested, the EGA-GCMS method proves to be an informed and comprehensive approach to material suitability testing that relies on the identification of compounds emitted from the sample along with some chemical intuition to assess how detrimental those compounds might be to a suite of artists' materials. Using this method, detection of non-corrosive but potentially deleterious materials such as solvents and plasticizers is possible whereas those materials would be undetectable using the standard accelerated corrosion methods. Additional consideration of the conditions of use, for instance direct contact with an artwork, may further impact the interpretation of these EGA-GC-MS results in terms of material suitability. In this way, this instrumental method provides a depth of assessment not possible with Oddy testing, while delivering a major advantage in terms of speed.

\section{Conclusion}

This correlation study demonstrates the potential of EGA-GC-MS for the rapid and accurate prediction of the suitability of construction materials for use in proximity to artwork without a lengthy accelerated aging stage. In most instances, the chemical reactivity predicted for emitted volatiles identified by this instrumental technique on metal artwork surrogates matched the observed corrosion found in traditional Oddy tests performed on the material in question. In one of the two instances where deviations from the expectation were observed, the instrumental approach proved to be more conservative-denying the use of a material that actually passed the accelerated corrosion test. The comparison described here, however, highlights the need for additional quantitative studies of VOCs, SVOCs, and inorganic gases emitted from construction materials and the adverse effect levels for these potential pollutants. Moreover, little information is available about the action of 
these compounds on different types of materials prevalent in artworks, e.g. plastics, metals, paper, leather, and colorants. As a more comprehensive understanding of the impact of various compounds on artworks becomes available, the correlation between judgements based on instrumental analyses and the observed performance of a material in the museum environment will be improved. Just as incremental improvements have increased the precision of the Oddy test [6-8], the subjectivity imposed by the reliance on chemical intuition in instrumental methods will decrease with increased experience and use, answering one of the 'grand challenges' of the cultural heritage preservation field for a technique capable of rapidly assessing a material's suitability for museum use.

\section{Authors' contributions}

All authors shared in sample preparation, data collection, and interpretation. All authors read and approved the final manuscript.

\section{Author details}

${ }^{1}$ Chemistry Department, Butler University, 4600 Sunset Ave, Indianapolis, IN 46208, USA. ${ }^{2}$ Conservation Science Department, Indianapolis Museum of Art at Newfields, 4000 Michigan Rd., Indianapolis, IN 46208, USA.

\section{Acknowledgements}

The authors are indebted to Drs. Chris Maines, Eric Monroe, and Eric Breitung for their helpful discussions during the course of this work. The installation crew and conservation staff of the IMA were invaluable in preparing and sourcing test materials. Dr. Victor Chen and Mr. Kurt Hostettler are recognized for their careful review of the manuscript.

\section{Competing interests}

The authors declare that they have no competing interests.

\section{Availability of data and materials}

Most data is available through the American Institute for Conservation's (AIC) materials testing wiki site http://www.conservation-wiki.com/wiki/Oddy_Tests :_Materials_Databases\#Results_Tables.

\section{Ethics approval and consent to participate}

Not applicable.

\section{Funding}

This research was funded in part by a National Endowment for the Humanities Research and Development Tier 1 Grant (PR-234564-16). Additional support was received through gifts from the Carter Family Foundation and the Frenzel Family Charitable Lead Trust. JM recognizes the Butler Summer Institute for its financial support.

\section{Publisher's Note}

Springer Nature remains neutral with regard to jurisdictional claims in published maps and institutional affiliations.

Received: 11 April 2018 Accepted: 31 July 2018

Published online: 06 August 2018

\section{References}

1. Hatchfield PB. Pollutants in the museum environment. London: Archetype; 2002 .

2. Wiegner K, Farke M, Horn W, Jann O, Hahn O. Tracing Pollutants: assessment of emissions from materials for museum equipment. Restauro. 2012;118:38-44.
3. Tétreault J. Airborne pollutants in museums, galleries, and archives: risk assessment, control strategies, and preservation management. Ottawa: Canadian Conservation Institute; 2003.

4. Erhardt D. Art in transit: material considerations. In: Mecklenburg MF, editor. Art in transit: studies in the transport of paintings. Washington, D.C: National Gallery of Art; 1991. p. 25-36.

5. Oddy A. An unsuspected danger in display. Mus J. 1973;73:27-8.

6. Robinet L, Thickett D. A new methodology for accelerated corrosion testing. Stud Conserv. 2003;48:263-8.

7. Green L, Thickett D. Testing materials for use in the storage and display of antiquities—a revised methodology. Stud Conserv. 1995;40:145-52.

8. Thickett D, Lee L. Selection of materials for the storage or display of museum objects., British museum occasional paper, no. 111 London: British Museum; 2004

9. Korenberg C, Keable M, Phippard J, Doyle A. Refinements introduced in the Oddy test methodology. Stud Conserv. 2018;63:2-12.

10. Tsukada FM, Rizzo A, Granzotto C. A new strategy for assessing offgassing from museum materials: air sampling in Oddy test vessels. AIC News. 2012;37:1-7.

11. Curran $\mathrm{K}$, Strlic M. Polymers and volatiles: using VOC analysis for the conservation of plastic and rubber objects. Stud Conserv. 2015;60:1-14.

12. Clark A, Calvillo J, Roosa M, Green D, Ganska J. Degradation product emission from historic and modern books by headspace SPME/GC-MS: evaluation of lipid oxidation and cellulose hydrolysis. Anal Bioanal Chem. 2011;399:3589-600

13. Gaspar E, Santana J, Lopes J, Diniz M. Volatile organic compounds in paper-an approach for identification of markers in aged books. Anal Bioanal Chem. 2010;397:369-80.

14. Godoi A, van Vaeck L, van Grieken R. Use of solid-phase microextraction for the detection of acetic acid by ion-trap gas chromatography-mass spectrometry and application to indoor levels in museums. J Chromatogr A. 2005;1067:311-36

15. Lattuati-Derieux A, Bonnassies-Termes S, Lavédrine B. Characterization of compounds emitted during natural and artificial ageing of a book: use of headspace-solid-phase microextraction/gas chromatography/mass spectrometry. J Cult Herit. 2006;7:123-33.

16. Lattuati-Derieux A, Thao S, Langlois J, Regert M. First results on headspace-solid phase microextraction-gas chromatography/mass spectrometry of volatile organic compounds emitted by wax objects in museums. J Chromatogr A. 2008;1 187:239-49.

17. Lattuati-Derieux S, Egasse C, Thao-Heu S, Balcar N, Barabant G, Lavédrine B. What do plastics emit? HS-SPME-GC/MS analysis of new standard plastics and plastic objects in museum collections. J Cult Herit. 2013;14:238-47.

18. Pastorelli G. Identification of volatile degradation products from Baltic amber by headspace solid-phase microextraction coupled with gas chromatography-mass spectrometry. Anal Bioanal Chem. 2011;399:1347-53.

19. Brown V, Crump D, Plant N, Pengelly I. Evaluation of the stability of a mixture of volatile organic compounds on sorbents for the determination of emissions from indoor materials and products using thermal desorption/ gas chromatography/mass spectrometry. J Chromatogr A. 2014;1350:1-9.

20. Mitchell G, Higgitt C, Gibson L. Emissions from polymeric material: characterized by thermal desorption-gas chromatography. Polym Degrad Stab. 2014;107:328-40.

21. Schilling M, Learner T. Evolved gas analysis as a tool for characterizing plastics. In: Bridgland J, editor. ICOM-CC 16th triennial conference. Lisbon: Critério-Produção Grafica, Lda.; 2011. p.1-11.

22. Schilling M. Identification and characterization of plastic artefacts: evolved gas analysis (EGA). In: Lavédrine B, Fournier A, Martin G, editors. Preservation of plastic artefacts in museum collections. Paris: CTHS; 2012. p. 70-3.

23. Samide MJ, Smith GD. Analysis and quantitation of volatile organic compounds emitted from plastics used in museum construction by evolved gas analysis-gas chromatography-mass spectrometry. J Chromatogr A. 2015;1426:201-8.

24. Gong Y, Wei Y, Cheng J, Jiang T, Chen L, Xu B. Health risk assessment and personal exposure to volatile organic compounds (VOCs) in metro carriages - a case study in Shanghai, China. Sci Total Environ. 2017;574:1432-8. 
25. Thepanondh S, Varoonphan J, Sarutichart P, Makkasap T. Airborne volatile organic compounds and their potential health impact on the vicinity of petrochemical industrial complex. Water Air Soil Pollut. 2011;214:83-92.

26. Rabl A, Spadaro JV. Public health impact of air pollution and implications for the energy system. Annu Rev Energy Environ. 2000;25:601-27.

27. Schwela D. Pollution, indoor air. In: Wexler P, editor. Encyclopedia of toxicology. 3rd ed. Oxford: Academic Press; 2014. p. 1003-17.

28. Grzywacz CM. Monitoring for gaseous pollutants in museum environments. Los Angeles: Getty Publications; 2006.
29. Shashoua Y. Conservation of plastics. Amsterdam: Elsevier; 2008.

30. Barnard PWC, Bunton CA, Llewellyn DR, Vernon CA, Welch VA. The reactions of organic phosphates. Part $\mathrm{V}$. The hydrolysis of triphenyl and trimethyl phosphates. J Chem Soc. 1961. https://doi.org/10.1039/JR961 0002670 .

31. Curran K, Možir A, Underhill M, Gibson LT, Fearn T, Strlič M. Crossinfection effects of polymers of historic and heritage significance on the degradation of a cellulose reference test material. Poly Degrad Stab. 2014;107:294-306.

\section{Submit your manuscript to a SpringerOpen ${ }^{\circ}$ journal and benefit from:}

- Convenient online submission

- Rigorous peer review

- Open access: articles freely available online

- High visibility within the field

- Retaining the copyright to your article

Submit your next manuscript at $\boldsymbol{\nabla}$ springeropen.com 